\title{
Making a case: reflections on the reader-text relation and the use of single and multiple empirical cases and generalization in sociological research
}

\author{
Joanne Gaudet ${ }^{1}$ \\ ${ }^{1}$ Department of Sociology, University of Ottawa, Ottawa ON K1N 6N5
}

Three encounters involving the case study approach during my doctoral research journey in sociology have spurred me to write this reflexive commentary on case studies. What I briefly explore here is how disciplinary-specific perspectives from readers engaged in reader-text relations appear to have entered into conflict with the relation of accountability I hold as an author with my texts and their underlying theoretical and empirical underpinnings. I first present an overview of the three encounters and then propose a short reflexive analysis for each.

During the first encounter, I engaged in relation with an editorial judgement from an anonymous referee who questioned the validity of a single empirical case. Given the ensemble of comments from the said referee, I gathered that he or she hailed from a discipline that favoured quantitative research with multiple cases. In a second encounter, I engaged with comments from an academic within sociology who questioned the validity of multiple (twenty-five) empirical cases and suggested the use of a single case instead. I had engaged with multiple cases in a context of interdisciplinarity with the natural sciences and in an area of research with limited empirical and theoretical scholarship mostly owing to access to data barriers. Finally, in a third encounter, I entered into relation with comments from an academic in anthropology who questioned the generalizability of a case study.

\section{First encounter}

In the first encounter, an anonymous referee put into question the use of a single case to illustrate a proposed theoretical approach. As a solution to the perceived problem in my single-case research design, the referee suggested that I engage in comparative analysis using the initial case and two or three additional cases. Comparative analysis according to the referee would generate data for contrasting cases and would therefore lead to 'more generalizable conclusions' and thus increase validity for the conclusions.

Anonymity meant that I could not ascertain the referee's discipline and disciplinary ontological and epistemological imperatives, but given the overarching trend in editorial judgements, I gleaned that he or she came from a discipline that favoured quantitative, not qualitative designs, where ontologically data were 'found' not 'constructed'. The disciplinary imperative seems to have translated into a request for more cases and therefore more 'found' data.

In my response to the referee, citing Flyvbjerg $(2001,2006)$ I outlined how it is not always optimal to use multiple cases. To construct one 'good' case, in this instance an extreme case of the proposed theoretical approach, could hold validity and be used for generalization. The case in question was also well contextualized as I had engaged in multi-method with qualitative methods (interviews and follow-up communication) in order to better understand relational dynamics. Overall, the underlying logic I outlined, in keeping with Flyvbjerg (2001), was that if the proposed theoretical approach rendered 
dynamics visible in an extreme case for which little to no dynamics were expected, it could certainly be expected to render dynamics visible in typical cases.

Throughout the review process, I maintained the relation of accountability to my research and single-case research design, that, in my view reflected ontological and epistemological coherence. To be fair to the referee, I had edited out case details in the manuscript in order to meet text length requirements and I must admit that case justification was minimalist (Gaudet, 2014a:13). A minimalist case description was nonetheless in keeping with papers already published in the chosen journal. The referee's editorial judgement did not solely address meager justification, however, he or she seems rather to have engaged in disciplinary imperatives to increase case numbers and increase data 'gathering' by changing the research design to comparative analysis that apparently would lead to 'more generalizable conclusions'.

Finally, the limited manuscript length was already problematic with one case, I can just imagine how a comparative analysis would have impacted word-count - having engaged in comparative analysis in my Master's degree - I predict plenty! From a reader's suggestion to adopt multiple cases, I turn to a suggestion to adopt a single case.

\section{Second encounter}

Diametrically opposite to the first encounter, in the second encounter a reader suggested that I discard a multiple empirical case approach in favour of a single empirical case, and should preferably espouse an ideal-type case. I surmised that the suggestion stemmed from the 'thinness' of proposed single case descriptions, as opposed to thick case descriptions that are typical in sociology (see Ragin and Becker, 1992). The quantity of cases also appeared to be problematic for the reader - twenty-five cases in all.

Calls to reduce the number of cases to one, from my perspective, went counter to the relation of accountability that I held to my empirical and theoretical research. First, I had identified limited theoretical and empirical research for my object of study and therefore could not reasonably expect a single case to help construct meaningful insights into potential relational dynamics. Second, one of the main limitations I had encountered ${ }^{1}$ during the investigation was absence of data due to structural barriers to access to data (Gaudet, 2014b:4, 21-22). Absence therefore translated into thin single cases and reliance on secondary data for single case descriptions. Yet, absence could also be understood as valuable data in itself (see Pascale, 2011:144; Rappert and Bauchspies, 2014; Gaudet, $2014 \mathrm{c}$ ) when understood in a multi-case context. Furthermore, there was at least some absent data for all cases. Thus, even if I opted to select only one case, it would remain thin.

In addition, the suggestion to build an ideal-type case was counter to my research design. I had constructed a theoretical paradigmatic case for which I was investigating multiple empirical cases (arguably including secondary data given absence of visible empirical data). Constructing an ideal-type case for a theoretical paradigmatic case struck me as an untenable proposition from a research design perspective. As a researcher, a two-part solution that I deemed acceptable given absence of data was: firstly, constructing empirical data (including on absence) and enlisting secondary data for the

\footnotetext{
${ }^{1}$ As had researchers before me, hence the limited empirical research in this area.
} 
twenty-five single cases, and secondly, exclusively constructing empirical data across cases.

With regard to multiple case data and analysis, scholarship does not exclusively support a single (or small case number) reporting approach as proposed by the reader in this encounter (cf., presenting data and analysis for single and cross-cases in the write-up; see related in Yin, 2009:170-182; Stake, 1995). In multiple case research it is not assumed that single cases must be presented and incorporated with multiple case data and analysis.

For example, Robert Stake, a researcher in education who mostly advocates small $\mathrm{N}$ case study research (Stake, 1995), performed a multiple case study with twenty-eight cases (Stake, 2006). Stake's approach for cross-case data construction and analysis (2006:chapter 3 and 9) corroborated my proposed multi-case approach and analysis (cf., construction of cross-case themes). Moreover, Stake's work (2006) confirmed that during the write-up phase, a focus solely on cross-case data and analysis instead of focusing on single cases and cross-case data and analysis is a justifiable option. Such decisions are part and parcel of multi-case decision-making by researchers (2006:6-7; chapters 3 and 9). Being fair to the reader in this encounter at this point means disclosing that I had not elaborated on multiple case research scholarship in the earlier draft under review.

To be sure, Stake (2006) and his research team constructed thick case descriptions, reflecting (relative) lack of barriers to the construction of visible data. In my research in contrast, I would argue that thin case descriptions due to absence did not impede cross-case analysis - they contributed to it. To neglect absence of data, I advance therefore, can contribute to reifying objects of study with absent data as 'natural'. This could prevent researchers from investigations owing to a disciplinary obligation of thick descriptions that rest on a need for 'presence'. Contrary to sociological research that can use coercion and bluffing in order to negotiate the disclosure of data from public entities such as governments (Piché, 2012:58), my object of study was known to meet high walls of secrecy and closure (i.e., Couzin-Frankel, 2013; Campanario, 2009). I multiplied requests for data - but to no avail. With the help of secondary data sources, and more importantly, accounting for absence, I constructed cross-case empirical data (Gaudet, 2014b:24-28). Here I thus met the imperative for only constructed empirical data in sociological empirical research - not from single cases, however - but from across cases.

Lastly, in the write-up I proposed tentative new directions for understanding the object of study (see Gaudet, 2014b:28-38) and explored how structural barriers for the construction of visible data could potentially be overcome in future research (2014b:39). Turning to the last encounter, reader comments on case study research can deal with elements other than case selection and research design; comments can address issues such as case generalizability.

\section{Third encounter}

The final encounter I explore is also diametrically opposite to the first encounterbut in this instance deals with generalizability issues. In the first encounter, the anonymous referee proposed that increasing the number of cases would increase generalizability. In this instance, a reader entrenched in anthropological ontological and 
epistemological footings advised that I should not to engage in generalizability based on case study analysis.

Anthropology is steeped in investigating situated practices and local understandings. As such, it therefore appears untenable to justify generalizability that might seemingly divorce situatedness and partial understandings from the intricacy of a case and its embedded actors.

In contrast, Compton-Lilly (2013) proposed that "[w]ell-argued case studies will neither argue for or against generalizability; but will identify the types of information and insights that extend beyond a particular case" (2013:61). The situated practices and local understandings in which actors were engaged in for my investigation revolved around a particular and shared ensemble of social relations: pre-publication journal peer review (traditional peer review). And it was the shared and particular ensemble of social relations that - at an abstract level outside any particular case or cases - commanded my attention beyond single cases. In the situatedness of single cases, however, I could explore the case-specific intersections of relations.

As a starting point, I fully agree and hold steadfast that a case, in and of itself, is situated and it is its situatedness that lends to deeper understanding. Borrowing from Stake (2006), Abbott (1992), and Flyvbjerg (2001, 2006), however, I address how my case study analysis lent itself to generalizability. To do so for me meant carefully using typical and atypical cross-case understanding to advance wider understanding (Stake, 2006:8, 10, 55; Flyvbjerg, 2006:73-77) for the shared and particular ensemble of social relations in traditional peer review. Generalization here was performed more as a conceptual exercise rather than a seemingly statistical exercise (Stake, 2006:8; related in Abbott, 1992). The high number of cases was not a statistical gambit - it was a conceptual gambit. It is the conceptual leap in generalizability therefore that I deemed as congruent with, and respectful of, case-specific situated practices and local understandings.

Nevertheless, I must admit that I hold reservations about ever being able to convince an anthropologist of the value of generalizability. I close with a few remarks.

\section{Concluding remarks}

Taken as a whole, the three case-study encounters discussed here have given me an opportunity to reflect on case study research and on the relation of accountability I hold with my research and writings. Potential conflicts can arise, it would seem, when an author's relations of accountability to research and texts enter into relation with a reader's relation of accountability to disciplinary imperatives. In the first encounter, a request for multiple cases seems to have stemmed from the reader's quantitatively oriented discipline. In the second encounter, a request for a single case appears to have stemmed from the reader's sociological preference for single and ideal-type cases with thick descriptions (mostly) in research that encounters little absence. In the third encounter, an aversion to generalizability seems to have stemmed from the reader's anthropological positioning. These encounters go beyond what can be expected from case study research per se (see review in Hyett et al. 2014) - they speak to intersecting relations among readers, authors, and texts. As a doctoral researcher meandering through the labyrinths of case study - I take pleasure in exploring and learning from such encounters! 


\section{References}

Abbott, A. 1992. "What do cases do? Some notes on activity in sociological analysis." Pp. 53-82. In Ragin, C.C. and H.S. Becker What is a case? Exploring the foundations of social inquiry. New York:Cambridge University Press.

Campanario, J.M. 2009. "Rejecting and resisting Nobel class discoveries: accounts by Nobel Laureates." Scientometrics 81:549-565.

Compton-Lilly, C. 2013. "Case Studies.” Pp. 54-65. In A.A. Trainor and E. Graue (eds.) Reviewing Qualitative Research in the Social Sciences. New York: Routledge.

Couzin-Frankel, J. 2013. "Secretive and Subjective, Peer Review Proves Resistant to Study." Science News 341:1331.

Flyvbjerg, B. 2001. Making Social Science Matter: Why social inquiry fails and how it can succeed again. Cambridge: Cambridge University Press.

—. 2006. "Five Misunderstandings About Case-Study Research." Qualitative Inquiry. 12:219-245.

Gaudet, J. 2014a. The 'Mobilization-Network' Approach for the Social Network Analysis of Knowledge Mobilization in Science Research and Innovation. uO Research. Pp. 1-28. http://hdl.handle.net/10393/31239.

—. 2014b. How pre-publication journal peer review (re)produces ignorance at scientific and medical journals: a case study. uO Research. Pp. 1-67. http://hdl.handle.net/10393/31198

- 2014c. "Absence and Presence in Science: Critical Reply to the Special Issue on Absences". Social Epistemology Review and Reply Collective. 3:4. 16-23. http://wp.me/p1Bfg0-1nm

Hyett, N., A. Kenny, and V. Dickson-Swift. 2014. Methodology or method? A critical review of qualitative case study reports. International Journal of Qualitative Studies on Health and Well-being. 9:23606.

Pascale, C.-M. 2011. Cartographies of Knowledge: Exploring Qualitative Epistemologies. Los Angeles: SAGE.

Piché, J. 2012. "The prison idea (un)interrupted: Penal infrastructure expansion, research and action in Canada". Doctoral thesis in Sociology. Carleton University.

Ragin, C.C. and H.S. Becker (eds). 1992. What is a case? Exploring the foundations of social inquiry. New York:Cambridge University Press.

Rappert, B. and W.K. Bauchspies. 2014. "Introducing Absence." Social Epistemology: A Journal of Knowledge, Culture and Policy 28:1-3. 